\title{
A virada comunicacional. Ou porque os estudos de "midiatização", de hábito e da Teoria dos Media passam ao largo da comunicação
}

\author{
The communication turn. Or because the studies "media coverage", of habit \\ and Media Theory pass off the communication
}

Ciro Marcondes Filho

Pesquisador de conceito 1A do CNPq. Bacharel em Ciências Sociais e Jornalismo (USP/SP), doutor pela Universidade de Frankfurt, pós-doutor pela Universidade de Grenoble (França), titular da Cátedra UNESCO José Reis de Divulgação Científica, é professor titular da ECA-USP desde 1987.

<ciromarcondesfilho@gmail.com>

\section{RESUMO}

\begin{abstract}
A semiótica fala de mudança de hábito como efeito mental, como modificação de tendências de uma pessoa em relação à ação, mas ignora o momento da passagem, a saber, o acontecimento comunicacional. O estudo político da dominação exercida pelos meios de comunicação (a teoria dos media) faz sociologia, é um estudo de tecnologias aplicadas à sociedade. A apropriação recente desses meios pela base social, pelas redes, não altera o caráter desse estudo, apenas sugere uma implosão da estrutura piramidal, verticalizada, para um uso mais horizontalizado. Estamos, portanto, ainda nos "meios", na mediatização. Não se justifica, portanto, contrapor o neologismo "midiatizar" à mediatização, pois é tautológico e só confunde. Comunicação ocorre através dos meios, ela é medial, mas não é obrigatoriamente mediática. É pelo medial que tudo deve começar.
\end{abstract}

Palavras-chave: Teoria dos media. Mediatização. Acontecimento comunicacional.

\begin{abstract}
Semiotics deals with habits change as mind effect, as modification trends of a person in relation to the action, but ignores the time of passage, namely the communication event. The political study of domination exercised by the media (media theory) does sociology, it is a study of technologies applicable to the society. The recent appropriation of the media by social basis through networks does not alter the character of its investigation, only suggests a collapse of the pyramid vertical structure to the benefit of its horizontal use. We are therefore still in the "media", in mediatization. There is no reason, therefore, oppose the neologism "midiatizar" to mediatization, it is tautological and only confuses. Communication occurs via the media, it is medial (das Mediale), but is not necessarily mediatic. Is in the medial everything should start.
\end{abstract}

A Academia não gosta de comunicar, não gosta da comunicação. Parece que quer se livrar desse termo incômodo, desagradável, desconcertante, porque lhe exige rever seus papéis e suas posições. A Academia prefere, em vez disso, falar em meios, nos media, ou mesmo na "mídia" ou na "midiatização", que remetem mais propriamente às formas de incomunicabilidade. Prefere discursar, 
pesquisar, produzir teses e livros sobre sistemas complexos de transmissão de sinais e dados, das redes telemáticas, dos processos rápidos de difusão, de toda essa parafernália de sistemas, equipamentos, redes, interconexões, tudo isso para não falar de comunicação. Falar de meios, mediatização, é fazer um discurso técnico, o discurso dos engenheiros, dos especialistas da inteligência artificial, dos desenvolvedores de programas e novos aplicativos. Isso não tem nada de comunicação, mas é para isso que tende a grande maioria dos estudos ditos "comunicacionais". Aqui e lá fora. E tendem a isso por pura dificuldade de comunicar e, no limite, pelo mal-estar de não poder discutir a própria comunicação.

\section{A semiótica não nos ajuda}

Digamos que os meios são o esqueleto, a ossatura, e a comunicação é o sangue. A analogia ainda é imprecisa, pois supõe duas coisas vivas, que crescem, se desenvolvem, se enfraquecem e degeneram. Contudo, a única coisa viva no processo comunicacional é a própria comunicação, que nunca está lá, já dada, para quem quiser fazer uso dela. Ela não é um signo, mas uma relação que se estabelece através de um uso particular e contextualizado dos signos. Ela não é um ente, que se interpõe entre dois sujeitos. Por isso, não cabe uma "análise de conteúdo", porque não há conteúdo já dado, constituído, esperando apenas ser decifrado. Champollion conseguiu decifrar a Pedra de Roseta, do delta do Nilo. Ele traduziu os caracteres em uma língua inteligível. Não obstante, o que ele fez foi apenas passar de uma língua a outra, o que nada tem a ver com a comunicação, pois o sentido desta se constrói única e exclusivamente no ato da leitura, quer dizer, diferentemente em cada momento em que a coisa é lida. É a "diferensa" de Derrida, algo que se pode pronunciar igual, mas que se escreve distinto (do termo "diferença"), sugerindo, com isso, o descolamento da relação entre significante e significado de uma interpretabilidade pré-definida, e poder, no diferir do tempo, em sua de-fasagem, comportar cada vez novas leituras.

Mesmo assim, nenhuma interpretabilidade pode aspirar uma tradução definitiva, sequer como os hábitos, de Peirce. Diz Santaella que "não há nada que possa melhor preencher a definição de interpretante lógico do que o hábito" (2004, p. 80). E aí ela cita Savan: a regra ou hábito, diz-nos

é um padrão de ações que, sob certas condições apropriadas, será repetido indefinidamente no futuro (grifo nosso). As ocorrências da regra ou hábito se dão em um conjunto particular de ações dentro de um período de tempo limitado. Esses conjuntos de ações particulares são interpretantes energéticos; mas, uma vez que exemplificam 
um hábito indefinidamente repetível, eles também são réplicas de interpretantes lógicos. Note-se que, enquanto os interpretantes emocional e energético têm uma terminação finita, o interpretante lógico é sempre potencialmente repetível sem terminação (Savan, 1976 citado por Santaella, 2004, p. 80).

O problema está exatamente nesse interpretante lógico e sua"terminação potencialmente repetível". Mas isso não existe. A mesma frase pode ser infinitamente repetida, mas terá, a cada vez, um sentido novo para os que a leem ou a ouvem, conforme sua organização mental nesse específico momento.

Diz Santaella,

faz parte do interpretante lógico, concebido como hábito, regular e governar ocorrências particulares, pois ele carrega alguma implicação concernente ao comportamento geral de algum ser consciente, transmitindo mais do que um sentimento e mais do que um fato existencial, quer dizer, transmitindo o 'seria' e o 'faria' do comportamento habitual. Ora, só o hábito é capaz dessa real continuidade, não apenas porque ele pode ser exercido em várias ocasiões, mas porque regula os eventos que ocorrem sob seu governo. Enquanto os eventos existentes são descontínuos, transitórios, o hábito é continuidade, garantia de que os particulares irão repetir-se de acordo com certa regularidade. É por isso que os hábitos precedem a ação e não vice-versa (Santaella, 2004, p. 80).

Hábitos são ocorrências viciadas, automáticas, que não requerem reflexão. Age-se maquinalmente. É o caso, por exemplo, dos estereótipos, das frases prontas, dos raciocínios-clichê, que vemos o tempo todo se produzirem na vida cotidiana, especialmente na política. Eles travam o pensamento, paralisam a reflexão, tornam o pensar algo mecânico, repetitivo, hábito. Santaella diz, contudo, na sequência desse mesmo texto, que não é bem assim, que hábito não é algo inflexível, que há sempre certa margem de flexibilidade na forma como ações são reguladas pelo hábito.

De fato, o agir e o pensar humanos são governados por formatos que seguem padrões. De fato, foi a partir daí que os engenheiros da inteligência artificial chegaram às tais das "máquinas inteligentes", já que casos particulares se repetem com regularidade. Mas agir e pensar não são governados só por isso. Há quebras de normas, raras, mas reais. É o que a professora chama de rupturas de hábitos, que criam novos padrões. "Pode ser provado que o único efeito mental que pode ser produzido e que não é um signo, mas é de uma aplicação geral, é a mudança de hábito, entendendo por mudança de hábito a 
modificação das tendências de uma pessoa em relação à ação" (Peirce, 1931-35 citado por Santaella, 2004, p. ?).

Peirce chama de "mudança de hábito" aquilo que chamamos de comunicação. Só que não. Eu posso deixar de fumar e me viciar em balas, deixar de ler este jornal para passar a assistir telejornal etc. Troco de hábitos. O problema está exatamente no hábito, pois ele nada tem a ver com a comunicabilidade. Quando um livro me transforma, quando um filme mexe com minhas concepções, quando uma instalação me faz rever meus padrões estéticos, estou falando de um choque, um salto qualitativo, um reposicionamento mental que passa a ordenar diferentemente meu mundo. Não se trata de repetição, substituição de uma leitura por outra, uma tradução por outra, mas efetivamente de um acontecimento. E isso escapa à semiótica.

Peirce é pragmático, não fenomenólogo. Está interessado na usabilidade prática dos signos para a ação. Já o fenomenólogo que saber o que efetivamente se passa com a mente do leitor, do telespectador, do fruidor. Que cortes estão ocorrendo aí. A mudança de hábitos é um processo quase mecânico de substituição, não é um salto para frente. Além disso, ela ocorre a posteriori, em função da vivência de outras experiências que nos atingem; já a comunicação estuda algo antes, especificamente esse encontro, esse choque com o diferente.

Existe uma sedução dos semióticos em se atrelar a regularidades e repetições, apesar de declarações em contrário. No Manual de Semiótica, Ugo Volli, por exemplo, diz que a semiose ilimitada de Peirce, só o é potencialmente, "pois no fim cada signo perde seu relevo necessário a posteriores interpretações" (Volli, 2008, p. 37). O que é isso, senão uma fixação metafísica, ou mesmo, uma aspiração à parada da semiose e à sua petrificação. O que falta à semiótica peirceana é exatamente o que sobra aos estóicos, a precedência do incorpóreo, aquilo que liquida definitivamente a visão de signo como um ente dado.

\section{Meios, "midia", midiatização não são comunicação}

Os meios de comunicação de massa não existiram sempre, tampouco foram tema dos debates político-filosóficos da era moderna. Por isso, antes de 1800, ninguém se questionava sobre a comunicação. A preocupação era outra. Talvez tenha sido Sören Kierkegaard o primeiro a levantar essa questão, ao constatar que entre o uso da tecnologia de massa para caluniar o outro e a velha forma de comunicabilidade criava-se um fosso.

O que faltava, na época, diz o filósofo, era "probidade". A campanha difamatória, da qual ele próprio foi objeto, sugeria que no sensacionalismo 
ninguém era íntegro e isso se devia ao abandono do "gênio primitivo", carecendose de uma "revisão do problema humano em geral" (Kierkegaard, 1854, p. 72). Por falta de probidade, continua ele, jamais se colocou a questão "o que é a comunicação?" (Kierkegaard, 1854, p. 73); para pensar isso, seria necessário distinguir duas coisas: objeto da comunicação e a própria comunicação. “De fato, nós já mostramos que o problema principal do pensamento moderno consiste em querer considerar, em toda parte, apenas aquilo que se deve comunicar - e não, o que é a comunicação" (Kierkegaard, 1854, p. 73).

Em poucas palavras, ele demarcou a diferença entre o mero falatório, a verborragia irresponsável e criminosa, em uma palavra, a discussão de mérito, e uma ideia de comunicar, que estaria associada à primitividade do homem, mas que ele não esclarece exatamente.

Kierkegaard, como boa parte dos principais filósofos do século XIX, foi levado a pensar a comunicação como problema a partir do jornalismo. Não obstante, a verdadeira revolução das ideias viria com a mudança da percepção advinda com o aparecimento da fotografia, anos 1820, e, 40 anos depois, da máquina de escrever, mas, principalmente, do fonógrafo e, por fim, do cinematógrafo, aparelhos esses que viraram o mundo de ponta cabeça e exigiram que os filósofos "baixassem a bola" e se voltassem para a revolução que estava acontecendo em seu dia a dia.

Aqui, o problema do registro se confunde com o da representação. O registro da imagem, da voz e do movimento instituem uma nova realidade medial, realidade essa que convive paralelamente à realidade propriamente dita, do mundo do trabalho, do lazer e da família. A nova realidade medial e a mudança da percepção daí advinda, levam o filósofo Edmond Husserl a rever as bases do saber, sugerindo, pela primeira vez, que nós, em nossos modos de ser, intencionalmente dirigidos aos objetos, nós, de fato, os constituímos.

Aqui, um novo argumento contra a semiótica. Considerando que a realidade mental e espiritual (ou intelectual) possui sua própria realidade, independente de qualquer base física, o filósofo desloca a atenção dos objetos - dos signos, dos símbolos, do que é culturalmente apresentado - para as reviravoltas internas que eles produzem na cabeça daquele que os recebe.

A nova realidade medial, especialmente a partir de 1900, incomoda os pensadores que começam a elaborar uma primeira avaliação crítica dos meios de comunicação. Se houve uma estupefação epidêmica diante das possibilidades do cinema, com os irmãos Lumière, espanto equivalente ocorreu, nos anos 1920, com a penetração generalizada das revistas e a massificação impetrada pelos 
grandes jornais. Karl Kraus, agora, de forma muito mais radical que Kierkegaard, denuncia a imprensa como o grande sabotador do pensamento iluminista: a campanha sem tréguas pela militarização, pelo revanchismo e pela recuperação do orgulho nacional teria levado, segundo ele, a Hitler.

Com efeito, os livros Propaganda in the World War, de 1927, de Harold Lasswell, Psicologia de massas do fascismo, de Wilhelm Reich, de 1933, Três flechas contra a suástica, de Serge Tchakhotine, de 1933, e a Obra de arte na época de sua reprodutibilidade técnica, de Walter Benjamin, de 1936, testemunharam o crescente pânico em torno dos perigos que os meios de comunicação passaram a representar para a democracia, a paz e a sobrevivência dos mais fracos. A obra Dialética do esclarecimento, escrita em 1943 e tida como um dos fundamentos dos estudos dos meios de comunicação de massas, veio posteriormente fechar o círculo.

Assim, a Teoria da Comunicação de Massa ou dos Mass Media teve seu início centrado, absolutamente, na questão política e a pergunta central com a qual a teoria deparou foi: como foi possível que a massa, sofredora e politicamente informada, tivesse aderido ao fascismo. Ou, como o formulou Deleuze em seu O Anti-Édipo: O que faz com que os oprimidos elejam e apoiem exatamente aqueles que são seus opressores, que desejem a repressão? Deleuze pensa na frase de Reich: "Os comunistas não levavam em conta que a consciência da massa não se compunha de elementos prontos e fixos, mas de elementos difusos, como, por exemplo, a fome, que por si só não forma nenhuma consciência" (Reich,1934, p. 13), complementando que este era exatamente o plano no qual escrevia em sua obra: a existência de objetos parciais, fluxos, corpos, que operam sobre uma grande superfície (o corpo pleno sem órgãos). Só há objetos parciais (fome, desejo sexual, de lazer) dispersos, que se remetem um ao outro e que vez por outra "rompem a parede do significante" (Deleuze e Guattari, 1972, p. 392), isto é, implodem com a significação que haviam tradicionalmente recebido.

A Teoria dos Media, como é denominada hoje na Alemanha, trabalha com isso. Seu objeto teórico é o estudo político da dominação exercida pelos meios de comunicação, hoje, também, pelos meios eletrônicos, como a internet e suas diversas plataformas de veiculação de matérias jornalísticas, vídeos, música e entretenimento. Não se trata de um estudo 
de comunicação, mas de tecnologias aplicadas à sociedade, um tipo de ramo da sociologia.

No Brasil, foi criada a curiosa expressão "mídia", que, em princípio não diz nada e serve para múltiplos objetos. "Mídia", que é como o brasileiro importou a pronúncia do termo inglês media, é, por vezes, inclusive, contraposto ao termo media (de mass media), o que faz com que os estudos brasileiros dessa questão tecnológica sejam totalmente ilegíveis para o leitor estrangeiro, visto que, para esses, é tudo "media" e quando nós fazemos essa separação, parece, aos olhos do leitor do exterior, que nossa ciência comunicacional não é séria.

Vejamos o termo"midiatização", defendido pelos teóricos da Universidade do Vale do Sinos. Segundo Fausto Neto,

não se trataria mais da 'era dos meios' em si, mas de uma outra realidade que se estruturaria a partir da atividade tecnodiscursiva midiática; [...] a linguagem perde seu'status representacional' e passa a se constituir no elemento central de um determinado processo enunciativo. De até então mediador, onde tinha autonomia relativa assegurada por suas competências discursivas, para enunciar as realidades, o jornalismo se vê diante de outra realidade constituída por complexos de 'feixes de relações', que se estabelecem a partir da midiatização junto ao tecido social como um todo $(2012$, p. 1).

A explicação, aqui, é a de que a linguagem, que na "era dos meios" era representacional, mediadora, assume agora a centralidade, e o jornalismo, segundo ele, constitui-se agora como "feixe de relações". O que era central, monopolista, torna-se múltiplo, plural. Não fica claro em que "midiatização" difere da mediatização, visto que se trata apenas de um deslocamento do eixo de poder, de um para vários, sendo que as tecnologias permanecem as mesmas, agora mais modernizadas, mas para ambos os lados.

Efetivamente, não há a mudança proposta. Fausto Neto diz que agora não são mais os valores-notícia nem as rotinas que definem os acontecimentos, mas são "vários atores e instituições não jornalísticas". Com efeito, alterou-se o modo de produção da notícia, mas a mediação sobrevive, agora não mais verticalmente, a partir dos monopólios, mas horizontalmente, pelas redes eletrônicas. O aumento da democracia e o desmoronamento dos impérios comunicacionais não justifica a construção linguística "midiatização" como oposta à mediatização, supostamente atribuída a tempos idos.

Isso porque o termo mediatização dá conta disso. Ele se refere pura e simplesmente ao uso dos media para certos fins. Mediatizar é realizar (o que quer que seja) com o apoio das tecnologias comunicacionais, não importa para que 
lado ou defendendo que interesses. É como o fármaco, que é tanto um remédio quanto um veneno, dependendo dos seus modos de uso. "Midiatização", ao contrário, veio para confundir, pois pretende positivar uma ação mediática invertendo seu polo, mas caindo numa tautologia inócua.

\section{Comunicação e seu objeto: de volta a Kierkegaard?}

Pedro Gomes, da mesma Instituição de Ensino, se pergunta - a esse respeito - qual seria o método adequado para se pensar a comunicação em geral e a "midiatização" em particular. Ele quer saber se o método hoje utilizado é o adequado para compreender o fenômeno em questão? (Gomes, 2012, p. 1). No caso, ele é o primeiro que se propõe a superar a barreira epistemológica que se constituiu na área, que busca excluir a discussão da comunicação, falando-se somente das tecnologias.

Para ele, "midiatização" é o fenômeno, objeto da comunicação, que se apresenta ao pesquisador em dois patamares:

No plano mais profundo, é a epifania da pessoa. Não há outra maneira de ela se manifestar a não ser pela comunicação. No espaço do fenômeno, entretanto, ela é uma exteriorização da pessoa enquanto tal. Como o ser humano é sujeito da linguagem, ele é um ser em comunicação. A pergunta pela condição de possibilidade da comunicação só pode ser feita pela comunicação e por ela respondida (Gomes, 2012, p. 2).

Epifania da pessoa sugere algo metafísico. Algo inominável, prélinguístico, expressão pura, um certo ar indecidível de cada ser humano. Portanto, não mediável. Logo, impossível de mediatizar (ou "midiatizar", como ele sugere), visto que mediar supõe obviamente um medium entre minha interioridade e sua expressividade. Temos aqui um primeiro problema. Pedro Gomes inverte a relação, tornando primário um processo que é, por definição, secundário.

A epifania de Gomes ocorre da mesma forma como sugere, de maneira menos filosófica, o Colégio Invisível, de Bateson, Watzlawick e colaboradores, em que a pessoa, bastando existir, já se comunica, "não há como não comunicar". Mas há a fala, a expressão intencional - esse seria o segundo plano -, que vai além do mero aparecer social. Neste segundo plano, diz ele, está implícita a pergunta pelo objeto da comunicação. E aí entram os dispositivos tecnológicos. Essas demandas, diz ele, só poderão ser respondidas "se nos debruçarmos sobre o ser da comunicação, 
buscando o que faz com que a comunicação seja comunicação, para além do fenômeno e da aparência" (Gomes, 2012, p. 2).

Kierkegaard, também se incomodava com uma ontologia da comunicação, mas desprezava o objeto da comunicação, o estudo de seus temas, sua virulência, seu abuso. Pedro Gomes quer saber - pergunta fundamental hoje, mais do que antes - se e como ocorre a comunicação na mediação tecnológica.

Como automanifestação do ser humano, ela é agente da realização do conjunto de relações constitutivas do 'nós' da sociedade. A manifestação do ser humano dá-se através da linguagem, que deve ser estudada dentro da perspectiva de sua exteriorização (Gomes, 2012, p. 2).

Certo, mas nada ainda justifica o uso do "midiático", pois estamos falando da mediação linguística, e mediático supõe os mass media como ligação, ou seja, a tecnologia, coisa que, em princípio, a linguagem humana prescinde.

Mas ele justifica:

\begin{abstract}
Volta-se, nesse momento, sobre a questão do método, com a qual se iniciou essa reflexão. A pergunta pelo objeto da comunicação, pelo seu ser mais profundo, é realizada através da própria comunicação, envolvendo, necessariamente, a indagação pela midiatização da sociedade". "Midiatização" - complementa ele em nota de rodapé - é a maneira de ser da sociedade. Isto é, uma sociedade em midiatização (Gomes, 2012, p. 2).
\end{abstract}

Veja-se que, para ele, o objeto não é o mesmo que para Kierkegaard, visto que objeto aqui se confunde com o próprio ser da comunicação, mantendo, contudo, ainda obscura essa vinculação à tal da "midiatização". Ora, por que motivo comunicação envolve necessariamente "midiatização"? Pelo uso da linguagem? Não seria defensável, pois as sociedades antigas deveriam ser, elas também, "midiatizadas", o que soa bizarro. A explicação é tautológica: não definindo exatamente o que é "midiatização", o discurso cai num círculo vicioso que o remete repetidamente, sem explicação plausível, ao ser da própria comunicabilidade.

Para melhor trabalhar essa questão, Gomes sugere, então, uma reflexão fenomenológica sobre os processos "midiáticos" e, por tabela, diz ele,

sobre o estatuto da comunicação a partir dos processos midiáticos, entendidos como conjunto de práticas comunicacionais pertencentes ao sistema de meios que opera segundo diferentes linguagens através de diversos dispositivos. Tais processos encontram-se 
potencializados com a emergência da tecnologia digital (Gomes, 2012, p. 2-3).

$\mathrm{Na}$ origem, portanto, não está a comunicação, mas as práticas comunicacionais vinculadas aos meios, operando com diferentes linguagens. Não está claro que meios são esses. Supõe-se que a pintura seja um meio, a escrita, outro meio, a oralidade, mais outro, não se podendo caracterizá-las necessariamente como "de massa", apenas como meios. Comunicação realizase através de meios, esse é seu modo de acontecer; isso diz como ela se dá, mas ainda não a caracteriza. Por outro lado, falar que a comunicação ocorre através dos meios quer dizer que seja medial, não mediática, visto que mediática, como dito acima, está subordinada à lógica dos mass media.

Comunicação, assim, deveria ser estudada - talvez não "a partir de", mas subsidiada pelo estudo de - processos mediais. E a tecnologia digital a colocaria em outro nível de medialidade, no nível - agora sim - do mediático. Dispensa-se igualmente, a terminologia aventureira do "midial".

Pedro Gomes está certo em batalhar por uma identidade própria dos estudos sobre comunicação, mas se equivoca ao dizer que sua centralidade "repousa nos processos midiáticos", quando, como demonstrado acima, ela pode ser, quando muito, subsidiada pelos processos mediais. O "midiático" vem só para atrapalhar.

Diz Pedro Gomes que

o estatuto da mídia como objeto de estudo torna-se um locus privilegiado para compreender a sociedade em seus diversos ângulos bem como os processos que a animam e a estruturam. Noutras palavras, a forma como o sistema midiático se constitui, com seus processos estruturantes e seus modos de produção, fornece ao pesquisador os elementos essenciais para elucidar os inter-relacionamentos sociais e humanos hodiernos. Nesse sentido, pode-se afirmar que centrar, epistemologicamente, a discussão e a pesquisa sobre a comunicação no domínio dos processos midiáticos significa realizar um percurso que objetiva identificar o seu objeto (2012, p. 3).

A tarefa de "compreender a sociedade" talvez seja um projeto por demais ambicioso. De qualquer forma, é campo de trabalho para sociólogos. Pedro Gomes diz que, para realizar tal empreitada, o "estudo da mídia" é locus privilegiado. A comunicação tecnologicamente mediada, de fato, fornece elementos para estudos sociológicos do presente. Mas ainda não chegamos à comunicação, continuamos no desgastado e academicamente saturado campo 
da sociologia. Se buscamos, de fato, uma identidade própria para os estudos de comunicação, é hora de sair desse barco. O centro epistemológico está fora da sociologia, fora da semiótica, fora da Teoria dos Media, está, efetivamente, no aprofundar-se em trabalhar a comunicação como fenômeno tout court. Só isso.

\section{Referências}

DELEUZE, G. e GUATTARI, F. L'Anti-CEdipe. Capitalisme et Schizophrénie. Paris: Editions de Minuit, 1972.

FAUSTO NETO, Antonio. Afetações da midiatização sobre o ofício jornalístico. Ambiência, Identidades, Discursividades e Processos Interacionais. Template para o I Encontro da Rede Nacional de Grupos de Pesquisa em Comunicação, Itapecerica da Serra, 2012.

GOMES, Pe. Pedro. Buscando o Objeto para encontrar a metodologia (a fenomenologia da midiatização). Template para o I Encontro da Rede Nacional de Grupos de Pesquisa em Comunicação, Itapecerica da Serra, 2012.

KIERKEGAARD, Sören [1854]. La dialectique de la communication éthique et éthicoreligieuse. Paris: Rivages Poche, 2004.

PEIRCE, C. S. [1931-35]. Collected Papers. ROBIN, Richard S. Annotated catalogue of the papers of Charles S. Peirce / Richard S. Robin. - Massachusetts: The University of Massachusetts Press, 1967.

REICH, Wilhelm. Was ist Klassenbewußtsein? Amsterdam, 1934.

SANTAELLA, Lúcia. O Papel da Mudança de Hábito no Pragmatismo Evolucionista de Peirce. Cognitio: Revista de Filosofia, v. 5, n. 1, 2004.

SAVAN, David. An Introduction to C. S. Peirce Full System of Semiotic. Toronto: Victoria College of the University of Toronto, 1976. (Monograph Series of the Toronto Semiotic Circle, 1).

VOLLI, Ugo. Manual de semiótica. São Paulo: Loyola, 2008.

Recebido em: 22 março 2015

Aceito em: 20 abril 2015

Ciro Marcondes Filho <ciromarcondesfilho@gmail.com>

Universidade de São Paulo - Escola de Comunicações e Artes - ECA

Endereço: Av. Prof. Dr. Lúcio Martins Rodrigues, 443 - Butantã

Cidade: São Paulo - SP - CEP: 05508-020 
Fone: (0xx11) 3091-4040 - ramal USP: 914040 